\title{
Analysis on Current Situation of Beijing Arts and Crafts Industry Exhibition Design
}

\author{
Jiang Li \\ The Department of art and design, Teachers' College \\ Beijing Union University \\ Beijing, China \\ sftlijiang@buu.edu.cn
}

\author{
Linxue Lv \\ The Department of art and design, Teachers' College \\ Beijing Union University \\ Beijing, China \\ sftlinxue@buu.edu.cn
}

\begin{abstract}
The Paper summarizes the data of Beijing exhibition industry development in recent years, extracts arts and crafts exhibition conditions, uses the way of classification survey and comparative study to cut modern display design elements, analyze the structure and design representation demands of Beijing arts and crafts class exhibition, and explore the communication of audience and exhibits and exhibits and space in the theme exhibition design, emphasizes the significance of brand exhibition in cultural values such as social education and communication functions, and summarizes appropriate methods and design characteristics of brand construction of Beijing arts and crafts class exhibition through a comparative analysis and study on the phenomenon of the design.
\end{abstract}

Keywords- brand exhibition; exhibition theme; design study

\section{INTRODUCTION}

From the perspective of the development of modern exhibition, brand exhibition is the best form to reflect the economic benefits embodied in the exhibition, and the social value created is much higher than that of ordinary exhibition. Major exhibition cities in the world have their own characteristic brand exhibitions, showing that the quantity of international brand exhibition becomes the standard to judge whether a city can be developed into an exhibition center. The study in the Paper on current situations of Beijing arts and crafts class exhibitions mainly includes the brand exhibition, the exhibition theme and design characteristics. Firstly, market analysis is made on the brand exhibition. In general, the following factors should be taken into account when defining whether an exhibition can create brand effect and the size of brand value: the industry leadership or professional and authority status of the organizers; whether the organizers possess the largest scale in the region or industry; whether social advocacy and influence can reach the maximum range in region or industry; organizers should have held exhibitions for 10 consecutive years or more; exhibitions are held regularly with stable time schedule; hosting sites are fixed or regular. As a brand exhibition, the exhibition theme and design characteristics can be reflected with a particular value and there is certain coherence in the representation. From the point of view of practicality of the exhibition design, it can be found that study value is closely related to social benefits created by the exhibition. The significance of design study on individual cases is not as great as the gained significance from brand exhibition study in terms of cultural value or economic value, so that the analysis made in the Paper is mainly for the demand of construction of brand exhibition.

\section{ANALYSIS ON THE BRANDS OF BEIJING ARTS AND CRAFTS INDUSTRY EXHIBITION}

As an important carrier to display design activities, exhibitions can be divided into two categories namely comprehensive exhibition and professional exhibition; for the scale of the activities, it can be divided into international, intercontinental, national and regional exhibitions. In general, comprehensive exhibition is featured by large scale and professional exhibition is featured by strong industry characters and professional attributes. With Beijing's rapid economic development, during "Eleventh Five-Year Plan" period, it accelerates the pace of construction of exhibition venues and facilities and the planning and management system for exhibition industry is gradually improved so that professional brand exhibition and exhibition tourism have become new economic growth points. Since 2006, the development of Beijing exhibition industry features obvious trend of year-by-year increase. In 2010, Beijing exhibition industry and related industry revenue reached RMB 17.25 billion, with an increase of $31.8 \%$ over 2009 [1]. With the international influence of Beijing increased gradually, the exhibition attracted more and more projects in the exhibition which can not only promote the development and growth of local brands, but also effectively promote the development of related industries. During the "Twelfth Five-Year Plan" period, based on the strategic objective of developing Beijing into "Asia's exhibition city", the cultural development of the functional core area of the capital is vigorously promoted, and cultural and creative industries and public cultural undertakings are developed which can be the strong and important foundation support for the nurturing and maturation of Beijing professional brand exhibition [2]. As the arts and crafts class exhibition which can reflect the regional cultural and artistic characteristics of Beijing best, it will be the focus of this study and the main references for basic study are based on the data of Beijing Exhibition Industry Development Report from 2008 to 2012, with the current design application phenomenon being a reference. 
There are many different types of cultural art exhibitions held in Beijing over the years, especially professional exhibitions, but with a serious lack of brand exhibition. Strictly speaking, "China Beijing International Cultural and Creative Industry Fair" is the only comprehensive arts and crafts exhibition with brand effects in the Beijing. Founded in 2006, Beijing Cultural Fair" is the only large-scale international cultural and trade fair which is themed by culture creativity; it established authoritative and representative exhibition brand value in the domestic cultural creative industry economy, thus creating a strong international influence and cultural economical attraction. It is usually held in November to December of each year, which has been held successfully for seven consecutive years. In addition to the main exhibition hall of each Fair, it also features multiple theme pavilions, with the content covering many areas of cultural industries, such as the " 5 th Beijing Arts and Crafts Exhibition" in the Sixth Beijing International Cultural and Creative Industry Fair sponsored by Beijing Economic and Information Technology Commission[3]. In addition, the brand effects of the " China International Gallery Fair", "Beijing International Art Fair", "Beijing Gift Show," "Beijing Redwood Furniture" and other professional exhibitions are relatively prominent. In a word, although the development of cultural arts industry in Beijing is leading in China, professional brand exhibitions are still incomplete.

The cultural art exhibitions in Beijing mainly belong to timeliness exhibitions, which are held according to prevailing industry activities, cultural environment or seasonal celebrations, but the professional exhibitions of well-known brands are less. According to the industry reports of various Beijing exhibitions from 2008 to 2012, it can be found that exhibitions that involve arts and crafts are numerous such as Gift Show, Redwood Furniture Fair, Antique Art Exhibition, Folk Art Exhibition, Art Seal Engraving Exhibition, Ceramics Exhibition, Jewelry Exhibition, Fine Arts and Crafts Exhibition, and Collection Exhibition, etc., throughout the Beijing Exhibition Center, China International Exhibition Center (old and new museums), the National agricultural Exhibition Center, China World Trade Center, the National Convention Center, the China Millennium Monument and other major exhibition halls. Most of the contents of the exhibition have national or international reach. The exhibitions which are specific to Beijing only include "Beijing Arts and Crafts Exhibition", "Beijing Folk Art Exhibition" and solo exhibitions of some practitioners or master craftsmen. Under this background, the number of professional exhibitions which belong to arts and crafts industry is large, but authoritative and national industry brand exhibition is not formed. On the national level, the exhibition with greater impact and wider scale in recent years was the "Chinese Contemporary Arts Biennial" held in the National Museum of China in April 2011, which was sponsored by the China Academy of Art China Intangible Cultural Heritage Protection Center. For it is in the form of Biennial exhibition, it will take time to observe whether it can be developed into an industry brand exhibition. In Beijing, the
"Beijing Arts and Crafts Exhibition" sponsored by Beijing Economic and Information Technology Commission is currently the regional professional exhibition with the best industry specifications and brand awareness, which is organized from 2003 to 2011 ( $1^{\text {st }}$ exhibition to $5^{\text {th }}$ exhibition), belonging Biennale type. The hosting site of the exhibition is not yet fixed and the brand effect needs to be further improved from the perspective of the publicity and influence.

TABLE I. $(2008,2010,2012)$ BEIJING ARTS AND CRAFTS INDUSTRY EXHIBITION:

\begin{tabular}{|c|c|c|c|}
\hline \multicolumn{4}{|c|}{$2008(10)$} \\
\hline Theme & Quantity & Continuity & characteristic \\
\hline ICCIE & 1 & Yes & complex \\
\hline Arts and Crafts & 2 & No & culture \\
\hline Jewelry & 2 & Yes & Business \\
\hline Mahogany furniture & 1 & Yes & Business \\
\hline Gift & 2 & Yes & Business \\
\hline Antique & 1 & No & culture \\
\hline Ceramics & 1 & No & culture \\
\hline \multicolumn{4}{|c|}{$2010(9)$} \\
\hline Theme & Quantity & Continuity & characteristic \\
\hline ICCIE & 1 & Yes & complex \\
\hline Arts and Crafts & 1 & No & Business \\
\hline Jewelry & 2 & Yes & Business \\
\hline Mahogany furniture & 1 & Yes & Business \\
\hline Gift & 3 & Yes & Business \\
\hline Master of Arts & 1 & No & culture \\
\hline \multicolumn{4}{|c|}{ 2012(11) } \\
\hline Theme & Quantity & Continuity & characteristic \\
\hline ICCIE & 1 & Yes & complex \\
\hline Arts and Crafts & 2 & No & Business \\
\hline Jewelry & 2 & Yes & Business \\
\hline Mahogany furniture & 1 & Yes & Business \\
\hline Gift & 3 & Yes & Business \\
\hline Classic Furniture & 1 & No & culture \\
\hline Arts and Crafts & 1 & No & culture \\
\hline
\end{tabular}

\section{ANALYSIS ON THE CHARACTERISTICS OF BEIJING ARTS AND CRAFTS INDUSTRY EXHIBITION THEME}

The exhibition theme is the outline guiding ideology throughout the exhibition. Each exhibition activity under planning needs a pre-established theme, which is the basis for the exhibitors to cooperate with each other with well division of labor under a unified and standardized basic premise, but also the key for ensuring that information on all aspects is consistent and accurate during design, manufacturing and operation; for audiences, their attentions can be caught in first time and their interest for participation in exhibition is inspired so that they can get a more comprehensive awareness for the entire event.

From the perspective of modern exhibition design, exhibition themes, exhibits and exhibition forms are inextricably linked: characteristics of exhibits determine the formulation of theme, specific exhibition form and demand of exhibits determine the spatial setting and performance results of the exhibition design. Most of existing arts and 
crafts exhibitions in Beijing are professional exhibitions, with the name formation being divided into two forms: the exhibition named by "geographical name + arts and crafts," and the exhibition named by exhibit type. The former one's industry specifications and influence are larger, which focuses on guiding, education and transmission demands for social culture, values and concepts; while the latter one focuses on the commercial motives, with the exhibition purpose being sales. For example, the "Beijing Arts and Crafts Exhibition" sponsored by the Beijing Economic and Information Technology Commission is featured by high overall level of exhibition, numerous exhibitors, a large number of visitors and huge social impact force, with the exhibition demand focusing on the display of cultural industry blending development results, so that the propaganda purpose is highlighted instead of the purpose of sales. While the sales purpose of Gift Show, Mahogany Furniture Fair and Ceramics Exhibition is emphasized. The themes of the exhibitions determined by the purpose of exhibitions are naturally provided with the two characteristics, which mean that the choice of theme needs help to achieve the purpose. Mainly for propaganda purpose of the show, the choice of the theme is helpful to the goal achievement. For propaganda-oriented exhibition, the theme selected is featured by strong attraction and tension and is equipped with guidance and emotional characteristics; while for sales-based exhibitions, straightforward themes will be selected, with a clear and concise expression characteristic. For the current exhibition market development, it is easier for the propaganda-oriented exhibition to manifest the brand effects, so as to develop the exhibition into a brand exhibition, thus generating more business benefits.

\section{Study ON THE DESIGN OF BEIJING ARTS AND CRAFTS INDUSTRY EXHIBITION}

Judging from the exhibition design elements, characteristics of exhibits will determine the exhibition form and space design. The exhibits involved in the Paper belong to arts and crafts exhibits and the study is made on design characteristics of brand exhibition for the exhibition positioning, so that the exhibition form and space design will focus on rendering cultural atmosphere. Compared to commercial exhibition form focusing on commercial sales function, more special exhibition ways are applied so as to highlight the cultural values of exhibits in the space design and emphasize the brand awareness and contribution made to the community and significance of the exhibition.

\section{A. Analysis on the Characteristics of Exhibition Form of Exhibits}

Exhibits in exhibition design refer to all kinds of physical exhibits at exhibition sites, which are designed as the material carriers for a variety of information transmission. From the perspective of design, this material carrier can be the exhibit itself or the exhibit model and patterns or images with a symbolic meaning. All exhibits involved in the Paper are arts and crafts, which are equipped with physical attributes and highly ornamental features, so that such exhibits are generally exhibited by two exhibition ways: separately or integrated exhibition, i.e. static display and multimedia display.

Static display is the most commonly used form of display in exhibition design, especially for exhibits with strong ornamental value. Such exhibits are directly connected with the exhibition theme so as to ensure that the audiences can directly obtain the appropriate information from the exhibits. During design, exhibits are usually being taken as a performance center, with a performance stage tailored for them. For arts and crafts, the stage should not only be provided with expressive function but be equipped with protection function. Factors from the environmental temperature and humidity requirements to security for prevention of thievery are emphatically considered by designers.

As the application of high-tech new media, multimedia exhibition is the exhibition form that makes use of a variety of images, models or artificial phenomenon to transmit information in the design. As a result, two patterns of manifestation are shown, namely viewable, reachable or operable. When they are being applied in arts and crafts, the former can be expressed as the video playback of recording creation process; while the latter is more complex, with the adoption patterns being selective and particular, which only applies to exhibits that are featured by simple on-site production and highly interactive function. In general, the function of exhibition form aims to transmit information beyond static display of exhibits to the audiences, so as to make audiences get a profound understanding of the process of formation of creative arts and crafts, as well as the creators' spiritual journey and concepts through watching or experience.

\section{B. Analysis on Characteristics of Exhibition Space Design}

Exhibition space is the site for exhibition, which is a specific space that can reflect the exhibition effect. Space is the most fundamental and universal form of communication, so that the role of space design in human social production and life is very important, which acts as the carrier of interaction between human beings. Designers need to create an environment that is able to achieve on-site communication and information transmission, and the word of "on-site" just implies "space" features, which means that all on-site communication and information transmission are occurring in a particular "space", and when multiple exhibits occur simultaneously in a space, the first thing in the viewers' brains is their position in the space and primary and secondary relationships so as to form the corresponding awareness. This communication generated through spatial language plays a prominent role in guiding or restraining audiences' behaviors, which is more effective than communication formed through language or text.

Arts and crafts exhibitions usually feature large-scale exhibition space, a large number of exhibits and booths, numerous audiences and lager demand on exhibition space reserved for booth space, so that the space design standard is higher than the space requirements on conventional spatial design exhibits. Design standards can be mainly reflected in the demand of space function. In general, design forms such 
as static displays, multimedia presentations, activity release or performances all belong to the scope of exhibition space design. In addition, according to the size of exhibition and number of audiences, the space design should also meet the requirements on communication, storage and rest environment which are often called auxiliary spaces or auxiliary facilities.

In an exhibition design scheme, the exhibition space design is an important part of the entire scheme and its spatial planning mainly involves two aspects. Firstly, the configuration relation of exhibits and exhibition sites; secondly, the dynamic line design for audiences in the exhibition space; the two aspects are complementary. In the design, the division of space can be divided into three types namely linear, complex and grid-type. For exhibitions that require larger exhibition space, the space form often occurs simultaneously in a combined form, such as a small space within a large space, and two or more large spaces combined by small spaces. Spatial planning principle is determined based on the characteristics of exhibits, or the necessary space form is selected based on the exhibition form of exhibits. The dynamic line led by the spatial connection formed by exhibits can be used for guiding the audiences' viewing directions, thus forming a complete tour of process.

Auxiliary space belongs to exhibition space, which will be in various exhibition spaces or displayed outside the display space, for the purpose of providing additional demand services for viewers watching the exhibition. It is used to provide viewers with a seating environment or provide a communication environment, which is a humanized design aspiration in exhibition services. As arts and crafts products themselves have a very strong ornamental feature, it is easy to form a more concentrated crowded spot, and can attract audiences' attention for a long time with the overall tour being long, so that it needs more humane and practical settings on the design of the auxiliary space. In the specific design, the pragmatic principle and the principle of adjusting measures to the local conditions should be followed.

\section{CONCLUSION}

In the Paper, through the analysis on Beijing Arts and Crafts Class Exhibitions from 2008 to 2012, with the combination of the existing design phenomenon, several issues on the text of the definition of brand exhibition, relation between the exhibition purpose and theme and the design characteristics of arts and crafts exhibition are analyzed and summarized. Firstly, emphasis is put on the significance and value of brand exhibition. Based on the analysis of current situation of Beijing Arts and Crafts Class Exhibition, we try to summarize brand exhibition construction goals and standards. Therefore, the design study is conducted against the exhibition purpose of brand exhibition and it points out that the topic should be determined based on publicity and education functions to highlight guidance and affectivity; emphasis is also put on characteristics of ornamental characteristics and security needs during exhibition of arts and crafts, so as to make the exhibit characteristics become the principles to determine the exhibition form and space design; for the exhibition form of arts and crafts, inductive selection is just made on the basis of existing forms, and the specific application program needs further confirmation with the combination of case demonstration.

\section{ACKNOWLEDGMENT}

Funded by Institute of Beijing Studies (Topic No.: BJXJD-KT2013-A05).

\section{REFERENCES}

[1] "Beijing Convention and Exhibition Industry Development Report 2011", University of International Business and Economics Press, Beijing, September 2011, p3.

[2] "Beijing Convention and Exhibition Industry Development Report 2011", University of International Business and Economics Press, Beijing, September 2011, pp. 57-74.

[3] "Beijing Convention and Exhibition Industry Development Report 2011", University of International Business and Economics Press, Beijing, September 2011, pp. 121-128.

[4] "Beijing Convention and Exhibition Industry Development Report 2009", University of International Business and Economics Press, Beijing, September 2010,pp. 157-168.

[5] Ying Lijun, "Governmental-Oriented Exhibition Development Report (2010)", People Daily Press, Beijing, November 2010.

[6] Huang Shihui, Wu Ruifeng, "Exhibition Design", Sanmin Books Co., Ltd. Taipei, August 2000.

[7] Wang He, "Exhibition Art Education", People's Publishing House, Beijing, October 2008.

[8] Cheng Xuesong, "Exhibition Space and Model Design", Shanghai University Press, Shanghai, December 2007. 